\title{
Article
}

\section{A Study in Reducing Cockling of Chinese Hanging Scrolls}

\author{
Jiann-Gwo Shyu ${ }^{1,2}$, Shih-Tsung Yu ${ }^{1}$ and Yuan-Shing Perng ${ }^{3, *}$ \\ 1 Department of Environmental Engineering, Da-Yeh University, Changhua 515006, Taiwan; \\ ag.hy@msa.hinet.net (J.-G.S.); yust@mail.dyu.edu.tw (S.-T.Y.) \\ 2 Wood Cellulose Division, Taiwan Forestry Research Institute, Taipei 100051, Taiwan \\ 3 Department of Forestry, National Chung Hsing University, Taichung 402204, Taiwan \\ * Correspondence: ysperng@nchu.edu.tw; Tel.: +886-4-22840345-152
}

\section{check for}

updates

Citation: Shyu, J.-G.; Yu, S.-T.; Perng, Y.-S. A Study in Reducing Cockling of Chinese Hanging Scrolls. Sustainability 2021, 13, 6843. https:// doi.org/10.3390/su13126843

Academic Editor: Maria L. Auad

Received: 24 May 2021

Accepted: 15 June 2021

Published: 17 June 2021

Publisher's Note: MDPI stays neutral with regard to jurisdictional claims in published maps and institutional affiliations.

Copyright: (c) 2021 by the authors. Licensee MDPI, Basel, Switzerland. This article is an open access article distributed under the terms and conditions of the Creative Commons Attribution (CC BY) license (https:/ / creativecommons.org/licenses/by/ $4.0 /)$.

\begin{abstract}
In this study, we attempted to investigate factors affecting the cockling of Chinese hanging scrolls from several practical aspects. From the experimental results, we found that artworks become more stable if they remain attached to a drying board for more than a month. After 3 months, they are nearly completely unaffected by changes in atmospheric humidity in the display space. Trimming the mounting silk in a direction either parallel or perpendicular to the weft makes a difference in the degree of cockling. If the lateral sides and top and bottom weft are perpendicular to the artwork height, the mounted artwork will cockle more than twice as much as when the weft of the painting as well as the top, bottom, and side borders are cut in the same direction. Artwork with a dry last backing mount will cockle less and have a more-uniform cockle height than that with a seated last backing mount. Regardless of whether a dry or seated backing mount is used, artwork that is attached to a drying board a second time will cockle less than one attached to a drying board only once. Waxing and stone polishing can also reduce the degree of cockling.
\end{abstract}

Keywords: scroll mounting; hanging scroll; last backing; cockle

\section{Introduction}

Ever since the introduction of hanging scrolls of Chinese painting and calligraphy, cockling of the scrolls has long vexed those who mount the scrolls. In this study, we investigated factors affecting the cockling of artwork and methods to ameliorate this problem. So-called "cockling" refers to the phenomenon when lying flat on a table or hanging on a wall, the lateral sides of a mounted artwork are often out of alignment to different degrees with the central line of the artwork. Hanging scrolls are the most prevalent form of mounted artwork, and they often appear to be cupped or cockled, causing an unsightly appearance and greatly detracting from the experience of appreciating the artwork. However, for more than a millennium, from the Xuei (581-618 AD) and Tang Dynasties (618-907 AD) to the present, the guild of artwork mounting has been troubled by the cockling problem. Most mounters regard this as being caused by changes in atmospheric humidity and an insufficient duration of drying on a drying board which result in the recto and verso having different shrinkage stresses, and hence cockling occurs. However, many scroll mounters will not openly divulge their experience in this regard, leading to loss of artwork through mishandling this issue. Furthermore, less experienced younger scroll mounters new to the trade are often at a loss as to how to overcome factors causing cockling. They regard these as enigmatic, not knowing which school of thought to follow in dealing with the problem. Thus, the situation is murky and demands systematic examination.

In both ancient and present-day books and literature, many factors are mentioned that affect the cockling of artwork - drying duration [1-5], humidity at the time of removal from the drying board [5-7], material shrinkage [3,6-8], fiber orientation [9], calender [3,4,7,9], beating brush [10], and paste [3,8]. The most often mentioned factor in the ancient literature 
regarding artwork flatness is the drying duration on a board. The longer the duration, the flatter the artwork becomes [3,5]. The practice of last backing (see "Definitions" below) refers to the procedure of pasting mounting silks around the artwork itself, pasting two layers of Xuan paper to the verso and then stretching it taut on a large, flat board with the recto attached to the board. Zhou of the Ming Dynasty (1368-1644 AD), author of The Log on Mounting and cited by Tu and Tu [9], mentioned that autumn is the best time for mounting artwork, and the longer the drying duration, the better the flatness of the mounted artwork. Furthermore, the weather when detaching artwork from a board should be dry; then cockling or cupping can be avoided. Zhou of the Ching Dynasty (1644-1911 AD) in his book Extending Appreciation to Unglamorous Artworks noted that spring and autumn are the best times to mount artwork, whereas the rainy season is not conducive to mounting artwork [5]. Although he mentioned that the drying duration affects the flatness of the mounted artwork, no experimental data were provided to prove how long the critical duration should be. Zhang of the Tang Dynasty (618-907 AD) in his Notable Paintings of Different Dynasties first proposed that unsized paper, bark, and straw-based Xuan paper or Lienxi paper (a kind of sheet made from tender bamboo culms which after waxing and stone-polishing appears to be very smooth) should be used to cover the verso of the artwork [5]. Shen [9] remarked that the diameter of the rolled-up scroll often critically affects whether or not the artwork will remain flat after it is hung.

There are also some studies on cockling of mounted artwork by Western scientists. Generally, they deemed that the presence or absence of cockling is greatly influenced by differences in shrinkage along various orientations [11]. They agreed that the dimensional stability of the paper substrate exerts a predominate influence on whether a mounted artwork will cockle. The dimensional stability of paper, in turn, is influenced by many complex factors and their interactions, such as the kind of pulp used, the degree of beating and cleaning, the orientation of the fibers, wet-end pressing, the degree of drying, and the addition of various chemicals [11]. There is also the idea that greater water absorptivity of paper is correlated with greater shrinkage and swelling [12]. Therefore, by reducing shrinkage of the paper, the shrinkage stresses of the paper will be reduced, and less cockling will likely occur. After many cycles of shrinkage and swelling, the release of internal stresses and hornification of the fibers prevent the paper from returning to its original state [11,13], or may lead to a state of permanent shrinkage [12]. When paper absorbs water, the swelling of fiber cell walls causes the paper to expand, whereas when it dries, linear shrinkage occurs [12,14]. A Japanese scholar found that when multiple sheets were glued together and the backing sheet had minimum shrinkage, swelling rates would cause the entire mounted paper to have uniform dimensional stability [15]. Another scholar found, however, that when multiple sheets were glued together, one of the plies being over-stretched or under-stretched could lead to a non-uniform structural performance [16]. After talking to some artwork mounters, most of them thought that the weather at the time of removal from the drying board should be dry, and the duration of the drying period should be more than a month. Manipulation of the last backing should take care to prevent excessive swelling of the paper or mounting silk, so that there is less shrinkage stress causing the detached material to cockle. Moreover, many practitioners consider that artwork that has been twice attached to the board will be flatter than that boarded only once. Twice attached to the board means that the last backing artwork is first pasted to a board, and after drying and being detached from the board, it is allowed to shrink, stretched taut, and reattached to the board. The second time around, the artwork is not sprayed with water, but rather water spray is applied after reattachment, so that the stresses are redistributed, and the artwork is stretched flat. However, in the present era, shortening the duration of mounting is more economical, and this lengthy practice is not in favor. A further critical reason is that there are many factors affecting the flatness of mounted works of art, and these factors have complicated interactions. Despite the interview results representing conclusions accrued from many years of work experience, there is no known scientific knowledge to back up their know-how. This is also a bottleneck encountered by 
many traditional crafts. In addition, the uncontrollable environmental humidity condition is another factor that vexes mounting practitioners.

The purposes of this study were to investigate the effects of factors, such as environmental moisture conditions, drying duration, pasting orientation of the mounting silks, boarding once or twice, modes of last backing, and waxing and stone polishing during the mounting process, on the flatness of hung scrolls, so as to discern the real causes affecting the flatness of these works of art and seek remedies. We endeavored to shorten the drying duration while still maintaining the flatness of the displayed artwork. The results can serve as a future reference for mounting artwork, thus increasing the overall level of mounting and the quality of displayed Chinese hanging scrolls.

\section{Materials and Methods}

\subsection{Terminology}

1. Hanging scroll: A format of presenting mounted traditional Chinese artwork mainly by suspending it on a wall for display. It is also one of the three main methods of storing Chinese artwork. Figure 1 is an example of a hanging scroll.

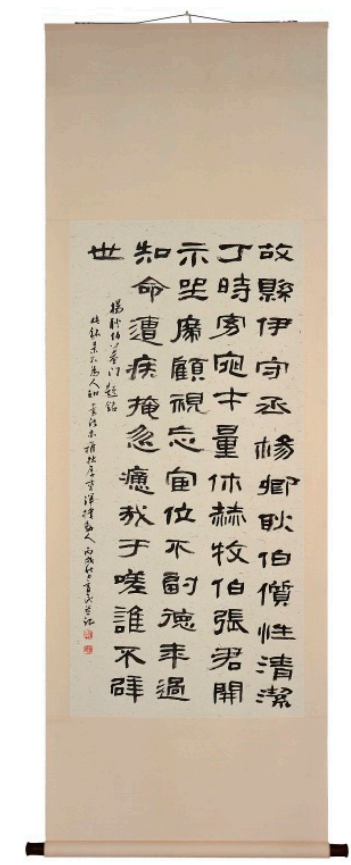

Figure 1. An actual sample photo of a hanging scroll.

2. Picture: An artistic creation, including both calligraphy and paintings.

3. Mounting silk: Framing materials pasted around the picture. In trade jargon, these are called mounting silks.

4. Artwork: A mounted piece, which consists of a picture and the surrounding mounting silk.

5. First backing: Brushing on starch paste to the verso of a picture using a pig-bristle or goat-hair brush, then using a palm brush (made of coarse leaf-sheath fibers of a palm tree) to brush on another sheet to the verso of the picture, tightly binding these sheets, and extending about $3 \mathrm{~cm}$ beyond the picture. When the sheets and picture are brushed together, extra paste is applied to the margin of the assembly, and the entire work is attached to a board to dry. This practice is called "first backing". Sometimes, backing the mounting silk with a sheet of paper is also referred to as first backing.

6. First backing paper: The sheets of paper pasted to the verso of a picture or mounting silk is called first backing paper. In particular, the backing paper pasted to the verso of a 
picture itself is called "min-tze" or "longevity paper", as the quality of this sheet greatly affects the life of a picture.

7. Last backing: When mounting silk is applied with paste and attached to surround the picture, drying of the paste results in shrinkage and overall rumpling of the artwork. Thus, a goat-hair or pig-bristle brush should be used to apply paste to a sheet of paper, then a stiffer palm-fiber brush is used to brush the sheet onto the back of an artwork. Next, paste is applied to the periphery of the backing paper and attached to a board to dry. This procedure in Chinese mounting jargon is called the "last backing", and the sheet of paper is called the "last backing paper". Traditionally, there are two plies of last backing paper in Chinese artwork mounting. The first ply is defined as the first last backing paper, and the second is defined as the final last backing paper.

8. Drying board: After completing the first backing and last backing, paste is applied to the picture and periphery of the artwork, and then it is attached to a flat board to dry. Usually when first put on the board, the paper assembly is moist. Therefore, when it dries because the periphery is attached to the board, the shrinkage effect stretches the paper flat. This board is called a drying board. The entire surface of a wall can also be substituted for a drying board, which is referred to as a "wall". Figure 2 shows a drying board and wall.

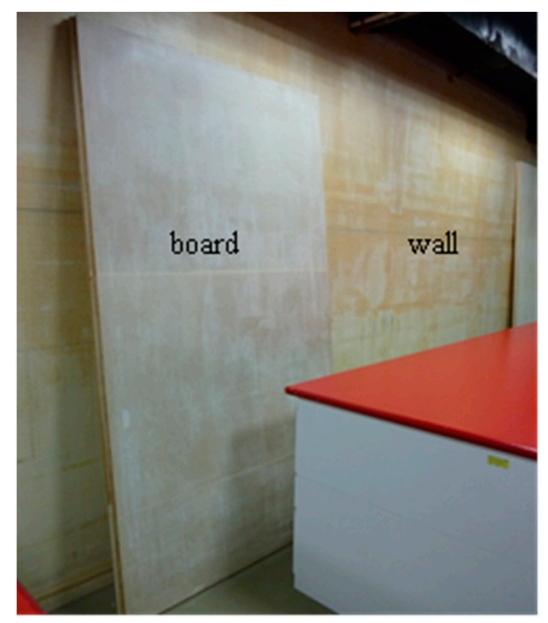

Figure 2. Drying board (left) and the wall (right).

9. Attachment to a board: After completing the first (or the last) backing, paste is applied to the periphery of the artwork and then it is attached to a board. Air is injected into the interstices of the board and picture, causing only the outer rim of the artwork to be attached to the board for drying. The procedure is called "attaching to a board".

10. Starch paste: Traditional paste used in mounting Chinese artwork consists of wheat flour with 3 to 4 times the volume of water; these are stirred together and heated until the paste turns transparent. Upon cooling, distilled water is added to the top for preservation. The water layer is replaced daily. When the paste is used, a portion is removed from the stock and filtered, then a suitable amount of water is added to reach a desired consistency depending on the procedural demand. Usually a pig-bristle or goat-hair brush is used to apply the paste to the paper, then the paper is placed on the verso side of the picture and the assembly is brushed flat with a palm-fiber brush.

11. Cockling height: After a mounted artwork is attached to a board for a predetermined period of time, it is lifted from the board and placed on a flat table. The difference in heights of the lateral edges with respect to the central line is called the cockling height. Figure 3 shows a schematic of this. 


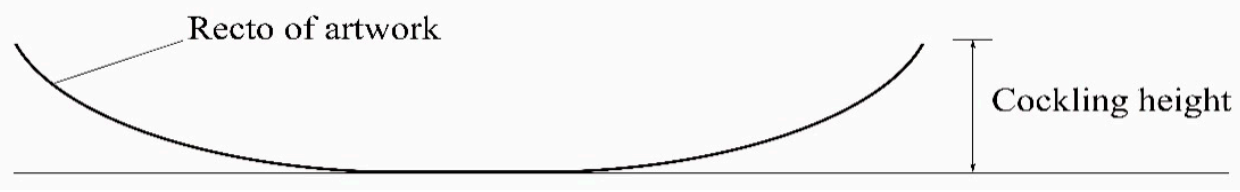

Figure 3. Schematic of showing how cockling height is measured.

12. Waxing and stone-polishing: After backing and boarding to dry for a designated number of days, the artwork is removed from the board, and with the recto facing down, is placed flat on a table. A layer of Chinese wax is applied to the verso of the artwork, then it is stone-polished with a smooth stone to make the backing sheet smooth and even. In the future, when rolled up for storage, the picture will thus not be abraded. Figure 4 shows the method of waxing and stone-polishing.

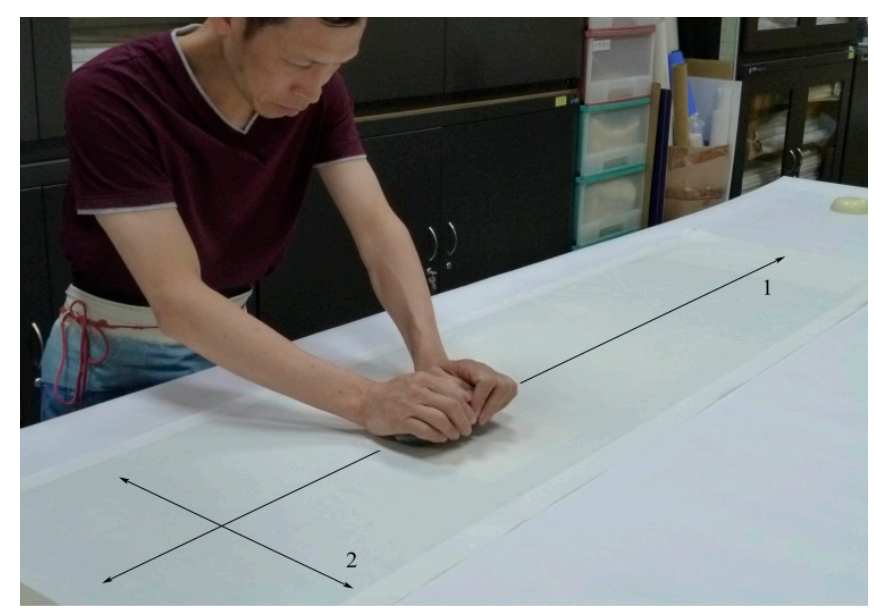

Figure 4. The directions of waxing (1) and stone-polishing (2).

13. Chuan wax (Chinese wax): a kind of wax used in artwork mounting. It is produced only in China, and the Szechuan Province of China has the largest production, hence the name. The wax is secreted by male bug communities of Ericerus pela Chavannes of the Coccoidea family (a scale insect) living on Chinese ash (Fraxinus chinensis), glossy privet (Ligustrum lucidum Ait.), or other plants of Ligustrum genus. The commercial product is obtained after refining. Traditional mounted artwork is mainly in the form of a scroll for ease of storage. Therefore, on the backmost year, a layer of thin wax is often applied so that when the mounted artwork is rolled, the back paper will not abrade on the picture. Another reason for using Chinese wax is so that after polishing, the backmost paper would appear smooth and not sticky. Hence, the picture will not be harmed or the pigment picked up.

14. Mounting of Chinese paintings and calligraphy involves the use of handmade paper which has a less-uniform consistency than machine-made paper. In order to avoid different papers affecting the experimental results, only blank Xuan paper was used in this study. The size and materials of the experiment are described as follows.

(1) The picture and first backing paper consisted of Hongxin brand Xuan paper (with $40 \%$ Pteroceltis sp. bark fibers and 60\% straw fibers) from Jing County, Anhui Province, China. It was produced in 2006.

(2) After pasting two sheets together and stretching the sheets taut, they were trimmed to $27 \times 60 \mathrm{~cm}$ in size.

(3) The mounting silk was used to back Hongxin 6-foot $(69 \times 138 \mathrm{~cm})$ Xuan paper from Jing County, Anhui Province, China. It was produced in 2006. The bonded sheets were cut to the desired sizes. The individual sizes are shown in Figure 5. 


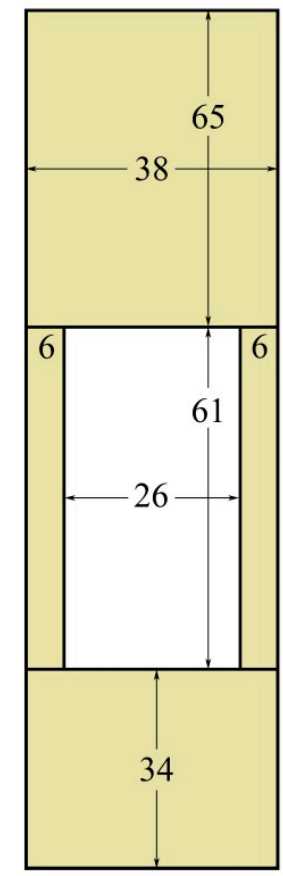

Figure 5. The dimensions of various parts of a hanging scroll.

(4) The last backing sheet was the same Hongxin 6-foot Xuan paper. Two layers were pasted to the verso of the artwork. Figure 6 shows the schematics of various layers of a hanging scroll.

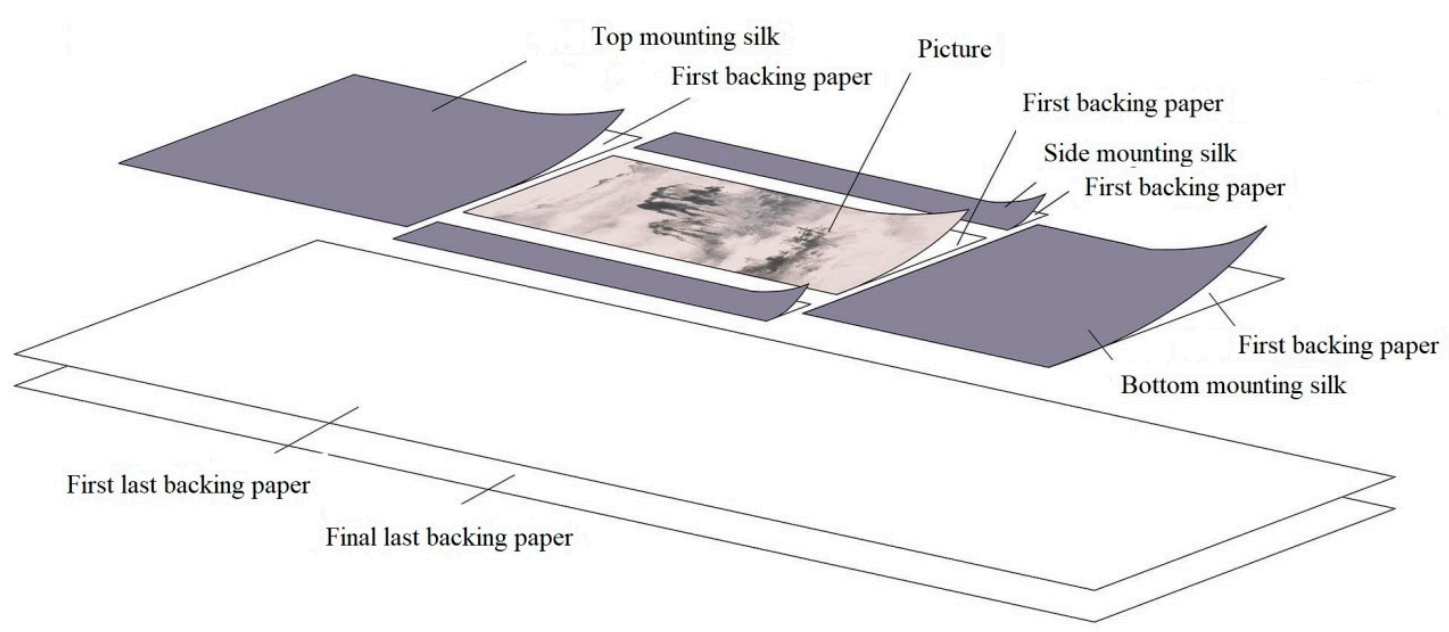

Figure 6. Illustration of various layers of a mounted hanging scroll.

(5) The mounting procedure is illustrated in Figure 7. Diagrams of the procedure are given in Figure 8. After drying and being detached from the drying board, all of the mounted works of art were placed in a room with respective constant temperature and humidity (CTH) of $23 \pm 1{ }^{\circ} \mathrm{C}$ and $50 \% \pm 2 \%$ relative humidity (RH) for $24 \mathrm{~h}$. Then, the degree of cockling of the side borders was measured, as shown in Figure 9. The cockling height was defined as how much the front, middle, and back edges of the two lateral sides of 24-h CTH room-conditioned mounted pieces lying flat on a table top deviated from the plane of the table. Each side was measured at three points and the average was taken as the degree of cockling. Figure 10 shows how cockling heights were measured at various locations. 


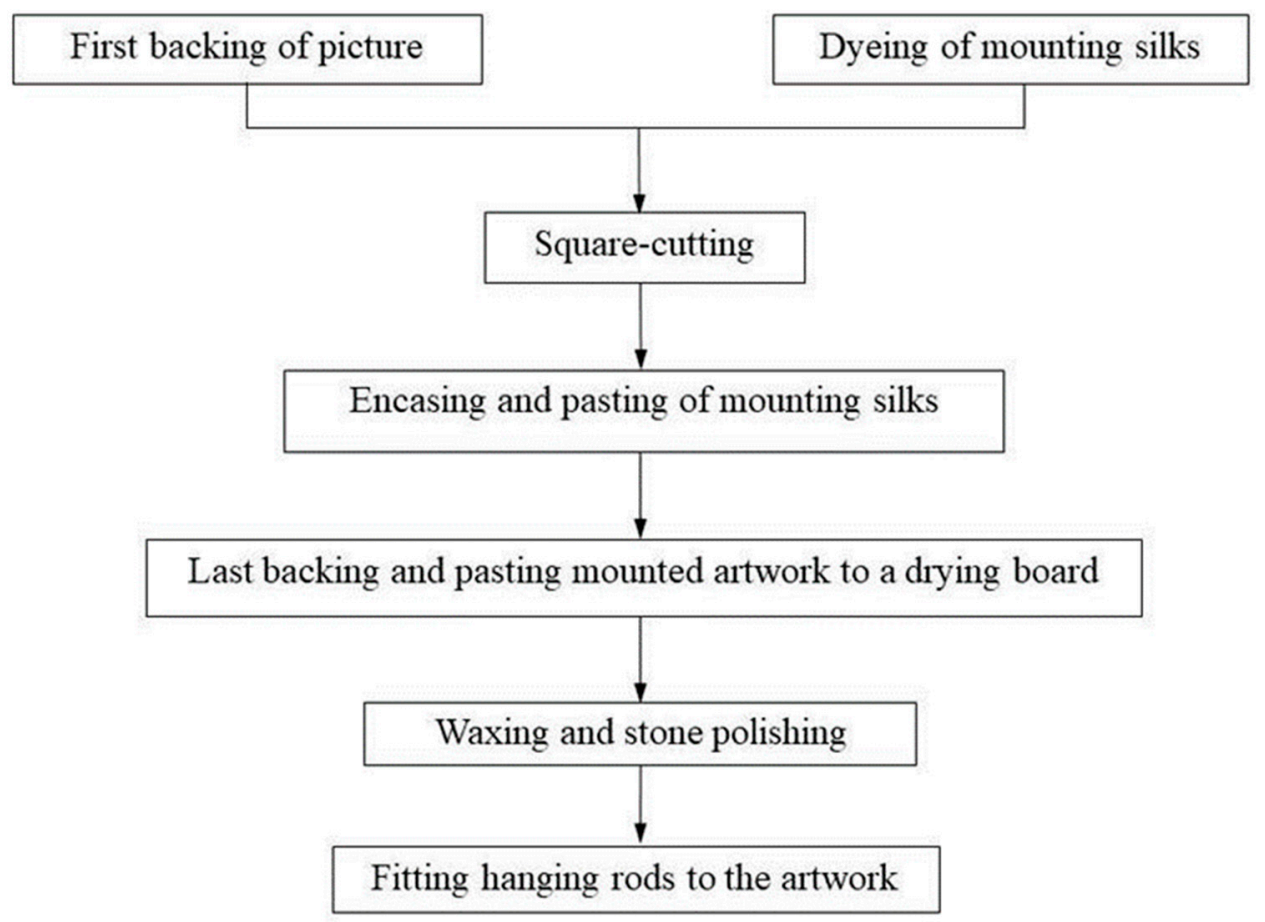

Figure 7. The main mounting procedures of a Chinese hanging scroll.

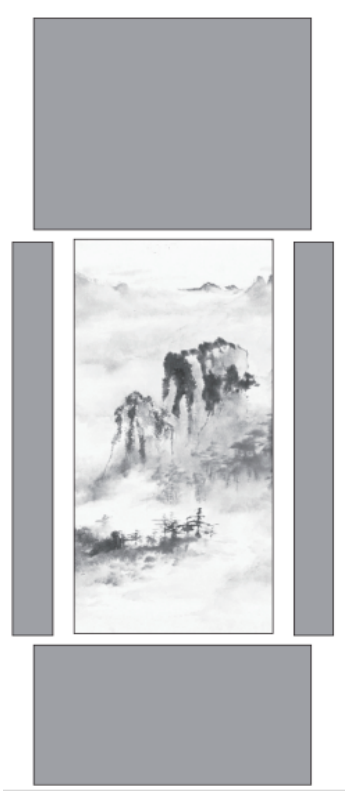

(a)

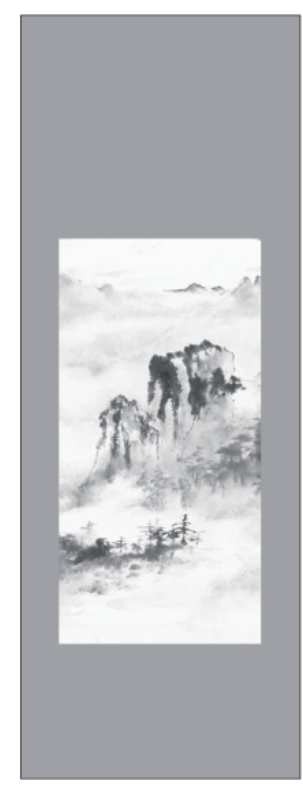

(b)

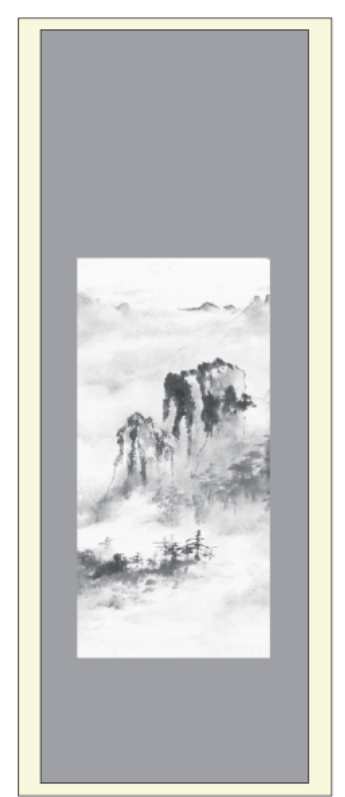

(c)

Figure 8. Simplified diagrams of mounting procedures of Chinese hanging scroll. (a) Picture and mounting silk; (b) picture and mounting silk framing together; (c) pasting last backing paper onto the verso of the artwork. 


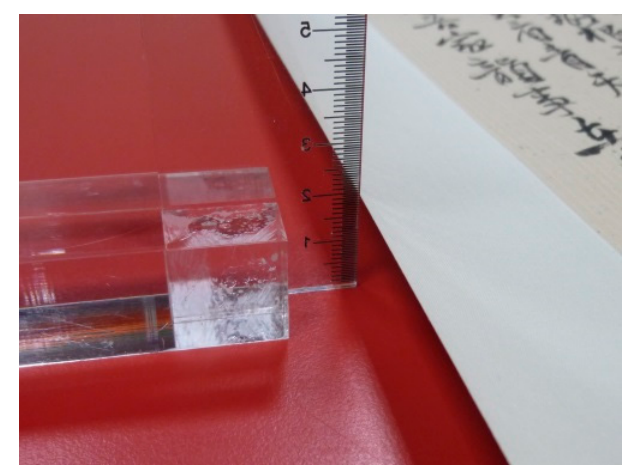

Figure 9. Measuring the cockling height of a mounted artwork.

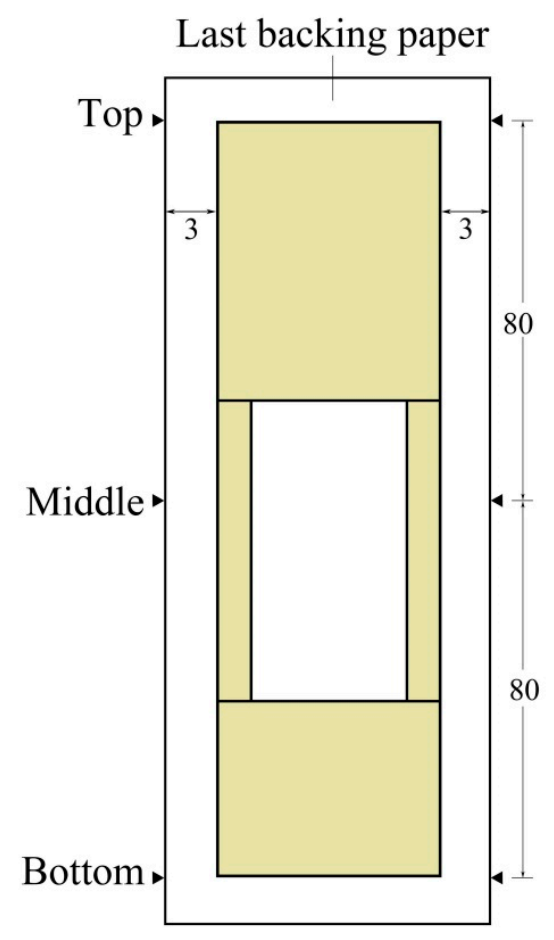

Figure 10. The locations where cockles were measured.

\subsection{Drying Duration}

After the last backing paper was attached to the mounted artwork, it was pasted onto a flat board for a predetermined duration. Then, the artwork was removed from the board and placed in a CTH room for $24 \mathrm{~h}$. The artwork was laid on a flat table top to measure the degree of cockling. The drying durations included 3, 4, 5, 8, 9, 10, 12, 14, 21, 28, 42, 60, 90, 180 , and 300 days.

The literature references mentioned a variety of time periods for the on-board time, namely $7 \mathrm{~d}$ [1,3], 7-10 d [2,4], 10-15 d [4,8], $30 \mathrm{~d}, 60 \mathrm{~d}$ [17], and $90 \mathrm{~d}$ [5]. We have included the pertinent references to the text. Traditionally, the on-board time is counted in days or weeks ( 7 days), or months (30 days) as units. Based on our prior experience, the artwork cockling was extremely unstable for an on-board time of 1-2 $\mathrm{d}$. Therefore, we set a period starting with $3 \mathrm{~d}$. Initially we opted for each alternate date for 2 weeks, then raised onboard time using a week $(7 \mathrm{~d})$ as intervals, and selected on-board times one week apart ( 21 and $28 \mathrm{~d}$ ), then with intervals of 2 weeks ( $42 \mathrm{~d}$ ), followed by 2 months ( $60 \mathrm{~d}), 3$ months (90 d), and eventually an interval of 3 months apart (6 months, $180 \mathrm{~d}$ ) and 4 months (300 d). 


\subsection{Humidity at the Time of Removal from the Drying Board}

Fourteen days after the artwork pieces were backed and attached to the board, they were detached from the board at RHs of $50 \%, 60 \%$, and $70 \%$, conditioned in a CTH room for 1 day, and then placed on a flat tabletop to measure their cockling heights. The procedure of backing and boarding is shown in Figure 11.

Different scholars pointed out that the humidity at the time of detaching from the board should optimally be $55-60 \%$ [8] or $60-65 \% \mathrm{RH}$ [2]. The predetermined $\mathrm{RH}$ for our lab was 50\%, hence, that was chosen. Then, at the $55-65 \%$ interval, we opted for $60 \%$ and selected $70 \%$ as an upper bound.

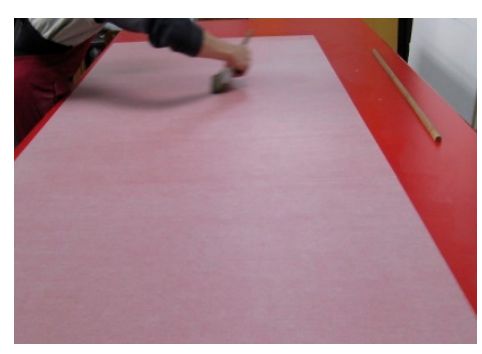

(a)

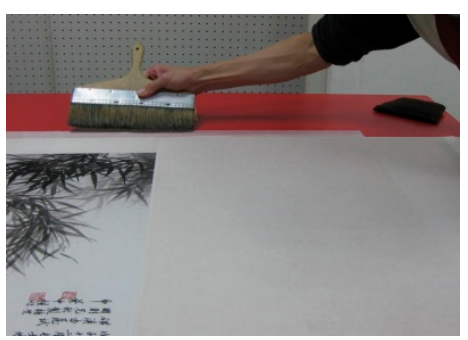

(d)

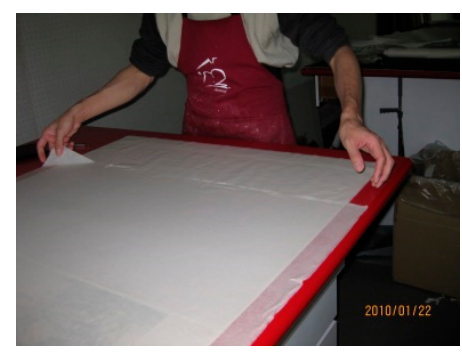

(b)

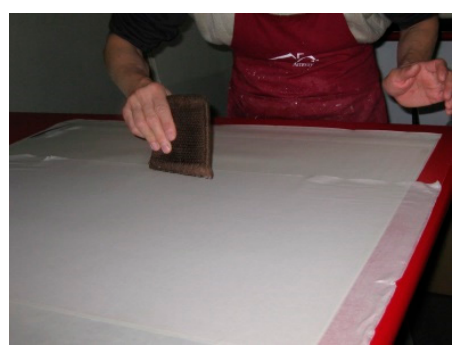

(c)

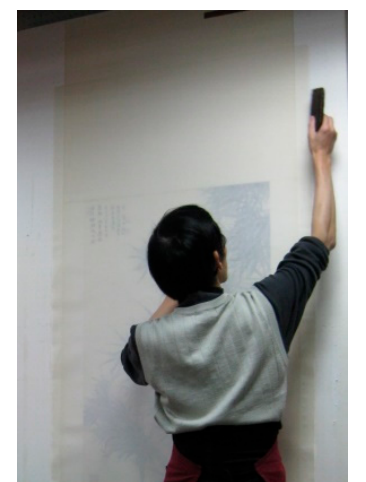

(e)

Figure 11. Procedure of putting on last backing paper and boarding the artwork. (a) Brushing paste onto the last backing paper. (b) Last backing paper covering the back of the artwork. (c) Brushing to remove air pockets in the last backing paper. (d) After the artwork is turned over, the paste is brushed onto rims of the last backing paper. (e) Attaching the artwork to a board to dry.

\subsection{Weft Orientation of the Mounting Silk with Respect to the Artwork Height Direction}

After the picture was mounted with mounting silk, stretched taut, and pasted to a drying board, the direction of the weft was oriented either parallel or perpendicular to the top, bottom, and sides of the picture. Before the artwork was pasted onto the board, the mounting silks were pasted together with the picture of the artwork in two specific groups: one with the weft parallel to the artwork height direction and the other with the weft direction perpendicular to the artwork height direction. Figure 12 shows the weft orientations in various scenarios. The artwork was removed from the board after 14 days as described above, and the cockling height was measured. 

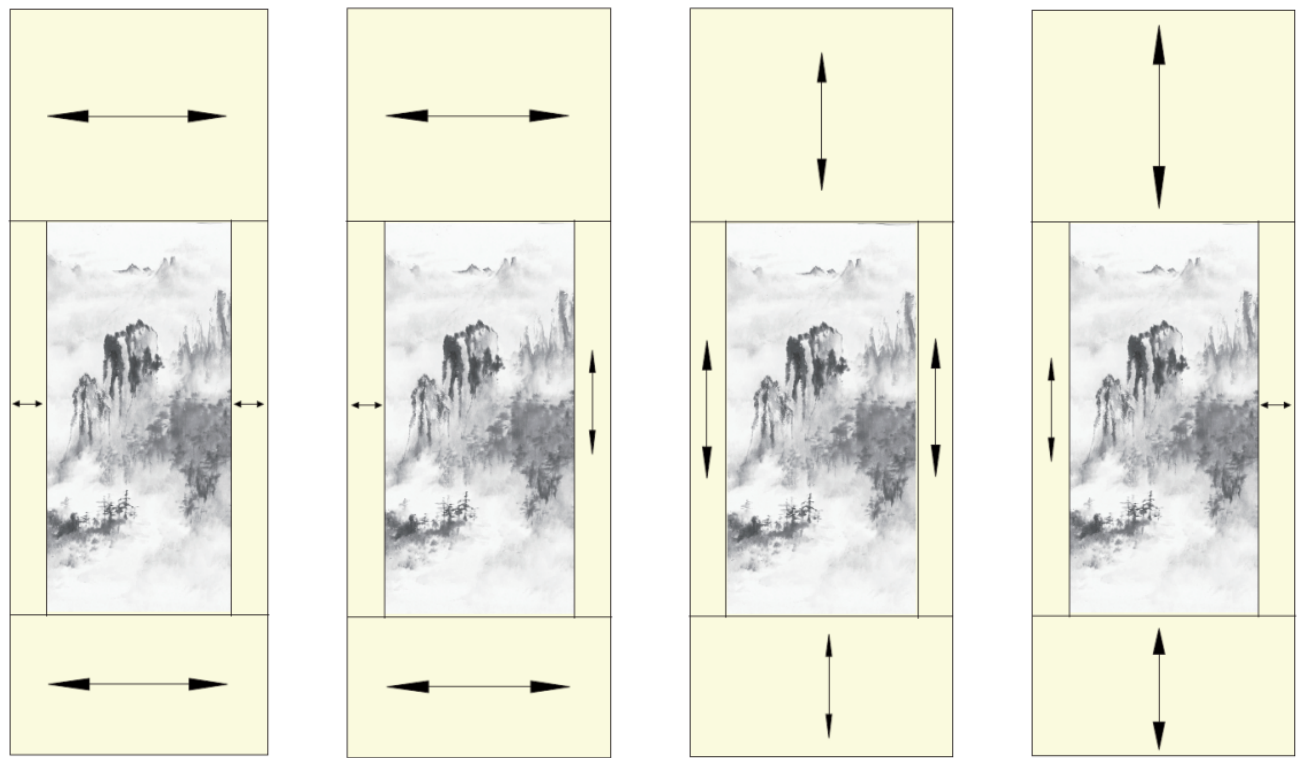

Figure 12. Weft orientation of mounting silks to the artwork height direction is shown (arrows show the weft orientation).

\subsection{Dry Last Backing and Seat Last Backing}

The artwork to be mounted was backed with Hongxin-brand Xuan paper as the last backing paper. There are two last backing methods in traditional Chinese mounting: dry last backing and seat last backing. So-called "dry last backing" refers to a work mounted with mounting silk and ready for last backing. The paste is brushed onto the last backing paper and extra moisture is absorbed from the verso of paper, then the last backing paper is applied by covering and brushing it flat and even onto the verso of the artwork. "Seated last backing" refers to artwork with paste applied to the last backing paper, and it is then laid flat with the pasted side facing upward. Next, the artwork, also facing upward, is placed onto the last backing paper to complete the last backing process. Figure 13 shows both processes of dry last backing and seat last backing.

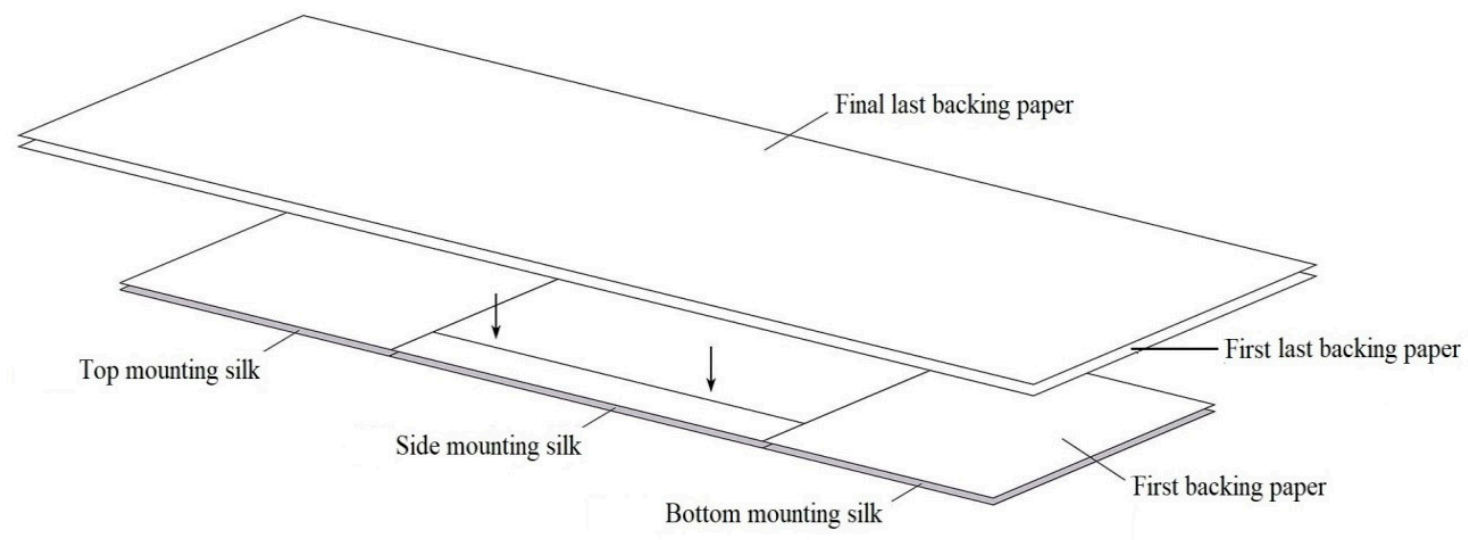

Figure 13. Cont. 


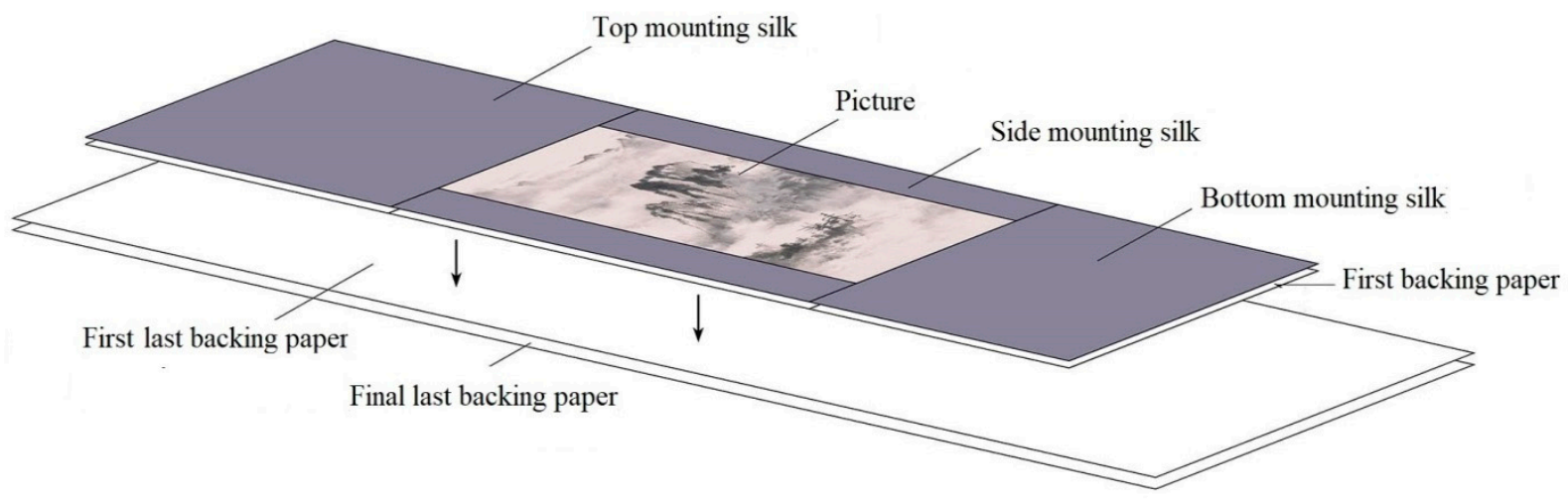

Figure 13. Schematics of dry last backing (upper) and seated last backing (lower).

\subsection{Attaching to the Board Once and Twice}

The works of art were separated into two groups, each with three replicates. One group was directly backed and boarded. The other group was backed and boarded, but upon drying, was removed from the drying board and placed in a CTH room to condition for $24 \mathrm{~h}$. Then it was pasted and attached to the drying board a second time. After a designated period (14 days), both groups were removed from the board and conditioned in a CTH room for $24 \mathrm{~h}$ before the cockling height was measured. The twice backed and boarded procedure is shown in Figure 14.

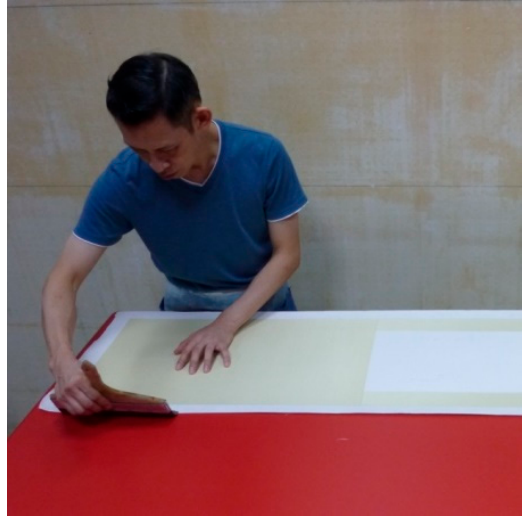

(a)

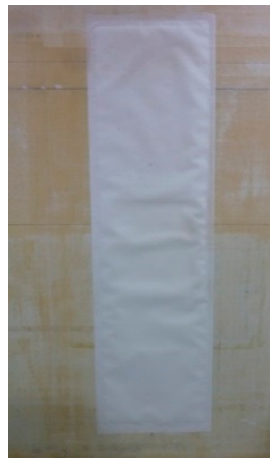

(e)

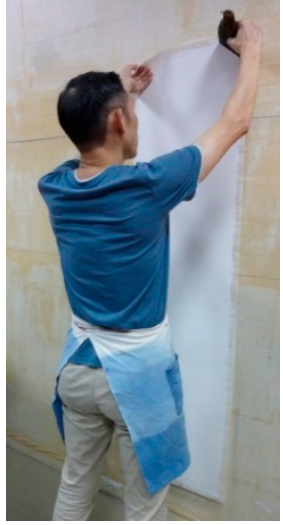

(b)

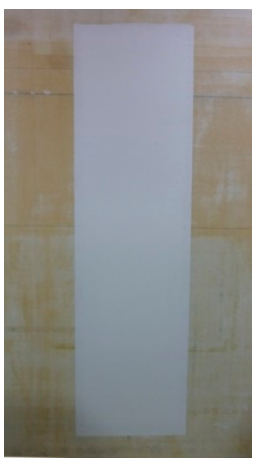

(f)

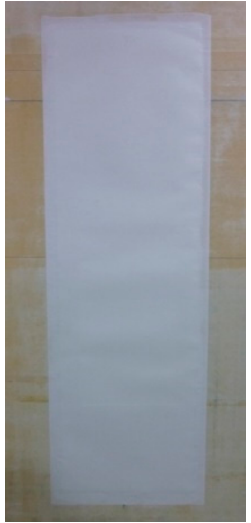

(c)

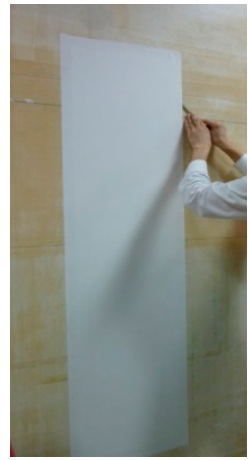

(g)

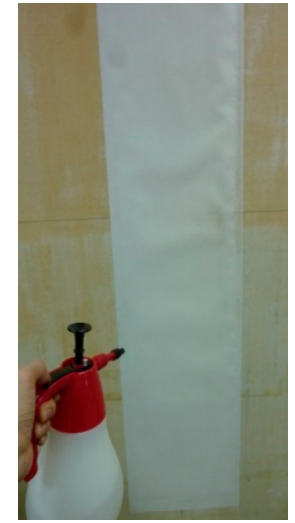

(d)

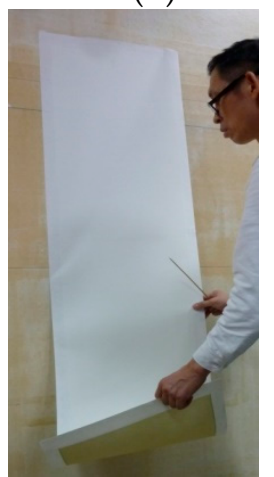

(h)

Figure 14. Cont. 


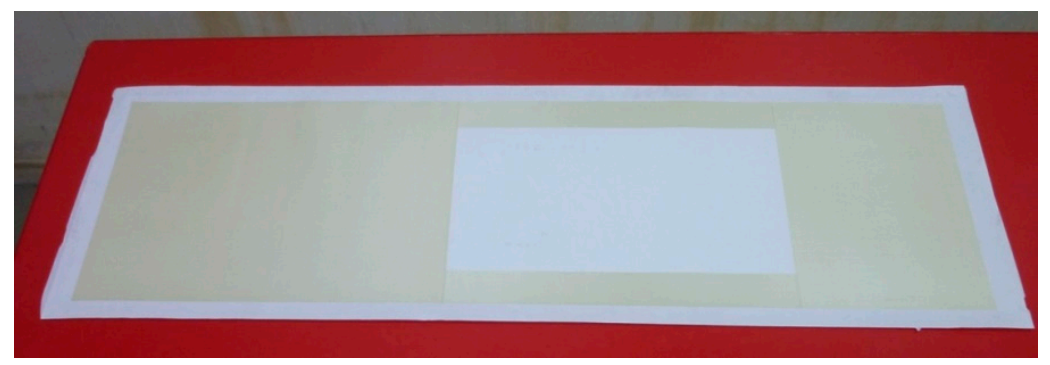

(i)

Figure 14. The procedure of twice boarding and lifting from drying wall. (a) One day after lifting the work from the board, paste is brushed onto the periphery of the backing paper. $(\mathbf{b}, \mathbf{c})$ Artwork is reattached to the wall. (d,e) Spraying water. (f) The artwork is stretched taut and flat. $(\mathbf{g}, \mathbf{h})$ Lifting the artwork from the wall. (i) The dried and tightened artwork.

\subsection{Waxing and Stone Polishing}

The backed works of art were put on a drying board to dry and were removed 3, 4, 5, 6, $7,8,9,10,12$, and 14 days later. These works of art were placed in a CTH room to condition for $24 \mathrm{~h}$; then, they were waxed and stone-polished. The cockling heights of the treated works were measured before and after treatment. Each condition was repeated three times and the average was determined to represent the cockling height and to calculate the standard deviation.

\section{Results and Discussion}

\subsection{Drying Durations}

Effects of the drying duration on the cockling height are shown in Figure 15. Results indicated that after 4 weeks, the influence of the drying duration abated. The cockling height was not stable for drying durations of 2 weeks or less. Theoretically, the longer the duration, the less cockling there is. However, the experimental results suggested otherwise. Works of art removed from the drying board at 6 and 7 days cockled more than those removed after 5 days. After this initial period, the cockling heights decreased with increasing drying durations from day 14 onwards. After 4 weeks, changes in cockling height began to stabilize. This agrees with a consensus from interviews that 1 month of drying duration is needed. The probable reason is that artwork attached to a drying board for a month undergoes cycles of wet-dry warm-cold shrinkage and swelling, causing the fibers to experience hysteresis of shrinkage and swelling, with a diminishing amplitude, which eventually slows the degree of cockling due to dimensional changes. For a drying duration of 300 days, even less cockling resulted. A drying duration of 300 days produced slightly less cockling than that with a duration of 180 days. The difference was nondiscernible to the naked eye, and both appeared quite flat and even to the public. For the length of attaching to the board, $t$-test results indicated that with an on-board time of 14 and 21 days, the artworks showed significant differences in their respective cockling heights (with $p<0.001$ ); whereas for the on-board times adjacent to these days, the resulting artwork cockling heights showed no significant differences. In both ancient and present-day literature, the drying duration should be long [3,5,8]. In the interim, the repeated shrinkage and swelling cause the dewatering curves to gradually merge, becoming insensitive to humidity changes, and the inter-fiber tensile strength weakens, causing the mounted artwork to be relatively more stable. This is conducive to a smoothing out of the mounted artwork [8,18,19]. Hsu [20] found that at $100 \% \mathrm{RH}$, paper reaches equilibrium with the ambient environment and hydroxyl groups absorb water. However, more adsorption is hindered by the crystalline structure of the fibers. During desorption, the absorbed water evaporates from the fibers and some of the existing hydroxyl groups on the fibers bind to nearby hydroxyl groups, forming a cross-linked state. When rewetted, these new cross-links limit moisture absorption, and thus, at the same RH, less water is absorbed. After several cycles of drying and wetting, with more cross-links forming each time, a 
cumulative maximum is eventually reached, water absorption of the paper gradually decreases, and its dimensional changes decrease. As noted in The Log on Mounting by Zhou of the Ming Dynasty, "the longer the drying duration, the better it becomes; so it should experience all the sunny and cloudy weather, dry and wet conditions to achieve a satisfactory condition". Usually, the drying duration should be at least 10-15 days for mounted artwork to gradually become flatter. The raw data of cockling heights of various drying durations of mounted artworks see Appendix A Table A1.

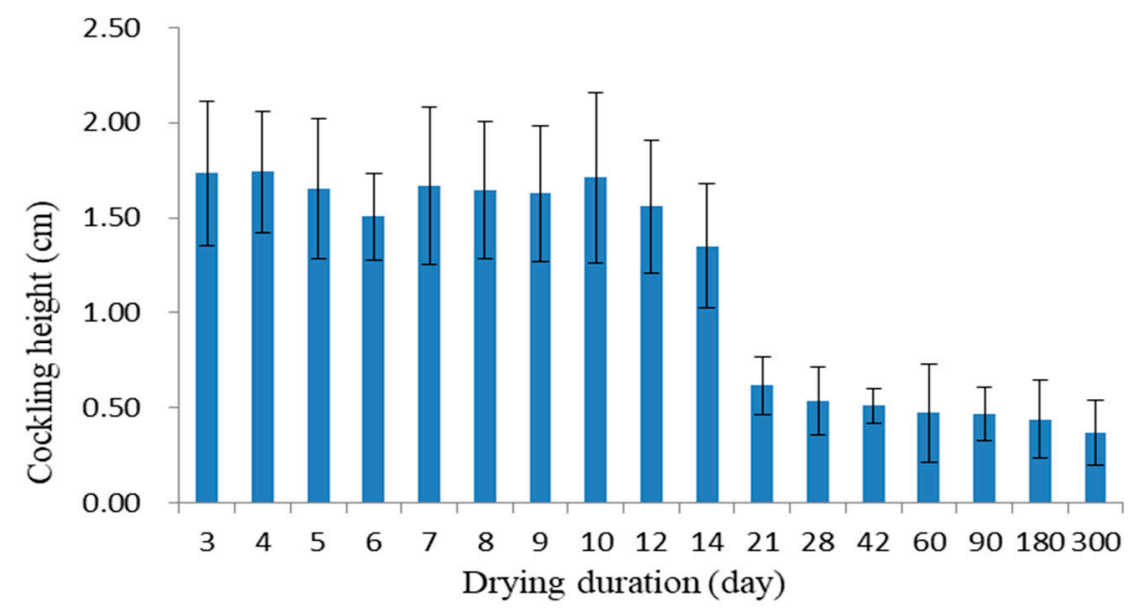

Figure 15. Effects of the drying duration on the cockling height of mounted artworks.

\subsection{Humidity at the Time of Removal from the Drying Board}

Drying durations in summer and winter should be longer than those in spring and autumn. This is also mentioned in The Log on Mounting by Zhou of the Ming Dynasty, which stated that removal from the drying board should avoid windy and hot weather, because a mounted artwork on a drying board is similar to a tightly stretched paper drum, and the drier the weather, the greater the tensile force of shrinkage becomes. If there is local detachment, the originally balanced stresses will be destroyed, causing the artwork to burst or even split. Therefore, the weather when lifting an artwork from a drying board should not be overly dry. Figure 16 is a schematic of artwork cracking due to an excessively dry moisture condition. After mounted works of art were backed and dried for 14 days, effects of humidities of 50\%,60\%, and 70\% when lifting the artwork from the drying board on cockling heights are summarized in Table 1. In our interviews with mounting experts, several of them mentioned that humidity at the time of lifting from the drying board affects the flatness of the artwork. The salient point is that if the mounting operational space has higher humidity than that of the exhibition space, then the artwork will appear flatter. Despite this, we found no definite trend with the three RHs we examined. An RH of $60 \%$ when lifting from the drying board produced better flatness, while RHs of $50 \%$ and $70 \%$ produced greater cockling heights. The $70 \% \mathrm{RH}$ condition produced the greatest extent of cockling. Hence, the RH at the time of lifting from the drying board should be neither too high nor too low. Excessively high humidity will cause the artwork to shrink when encountering a drier environment, leading to unevenness, while excessively low humidity will also cause cockling due to different shrinkage rates before and after lifting the artwork from the drying board. 


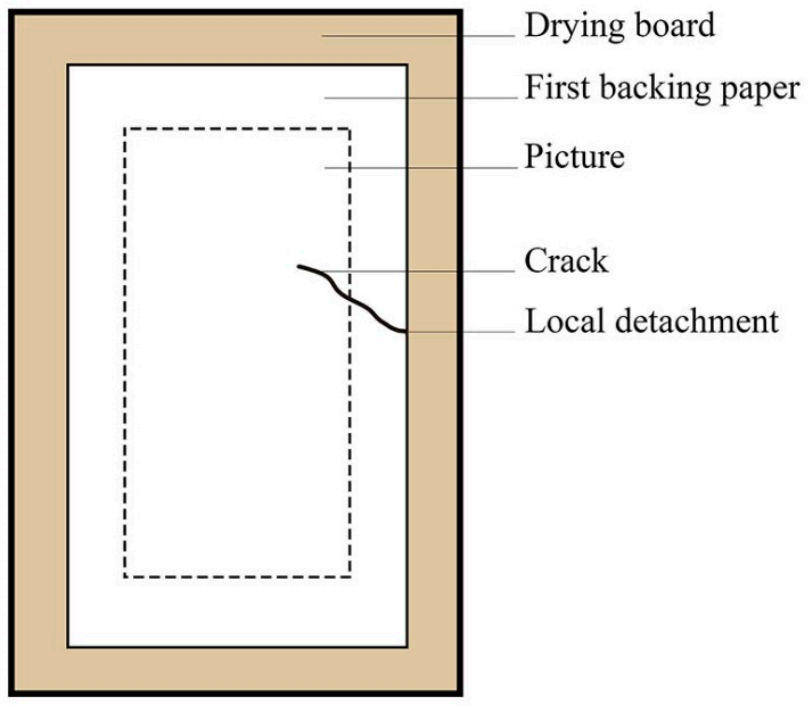

Figure 16. Schematic showing the effect of an excessively dry moisture content during lifting from the board which can cause the artwork to crack.

Table 1. Effects on cockling heights of the ambient relative humidity $(\mathrm{RH})$ when lifting mounted artwork from a drying board.

\begin{tabular}{cccc}
\hline RH when lifting from a board $(\%)$ & 50 & 60 & 70 \\
\hline Cockling height $(\mathrm{cm})$ & $0.99 \pm 0.16$ & $0.77 \pm 0.05$ & $1.15 \pm 0.20$ \\
\hline
\end{tabular}

\subsection{The Mounting Silk Weft Orientation with Respect to the Artwork Height Direction}

Effects of the mounting silk weft orientation being parallel or perpendicular to the artwork height direction and the ambient humidity (50\% and 62\% RHs) when lifting artwork from a drying board are shown in Figures 17 and 18. From these Figures, it is clear that regardless of the humidity at the time of lifting from the drying board, with the mounting silk parallel to the artwork height direction, the mounted works of art were generally flatter and less cockled. The $t$-test results indicate that Figures 17 and 18 show that when weft of the fabric respectively parallel to and perpendicular to the lengthwise direction of the artworks, the resulting cockling heights were significantly different (with $p<0.001)$. Conversely, when the weft of the mounting silk was perpendicular to the artwork height direction, two-fold greater cockling heights were observed. The main reason is that when making the mounting silk, the warp is often already fixed and tightly maintained by the weft lines traversing the warp using shuttles to produce the textile. The shuttle speed causes the weft to have greater shrinkage stress than that of the warp; in addition, the backing paper sheets pasted to the mounting silk have less shrinkage stress than the mounting silk itself. Hence, the mounted silk often deforms more along the weft direction than the warp direction. When the weft orientation is perpendicular to the artwork height direction, the difference in the overall cockling stress is small and the artwork appears flatter. Effects of the weft and warp directions and the $\mathrm{RH}(60 \%$ and $75 \%)$ when lifting artwork from a drying board on the cockling height are summarized in Table 2. The table shows that a greater shrinkage stress in the weft direction caused greater cockling heights, and it was more susceptible to the influence of humidity. The higher the humidity, the less the shrinkage stress, and the lower the cockling height; conversely, the lower the humidity, the greater the shrinkage stress, and the greater the cockling height. As for the warp direction, regardless of the humidity conditions, the cockling height remained stable. Thus, when trimming mounting silk to mount an artwork, the weft direction should be parallel to the artwork height direction; then the resulting mounted artwork should exhibit less cockling. The raw data of cockling heights of the weft direction of the mounting silk to the artwork height direction of the mounted artwork see Appendix A Table A2. 


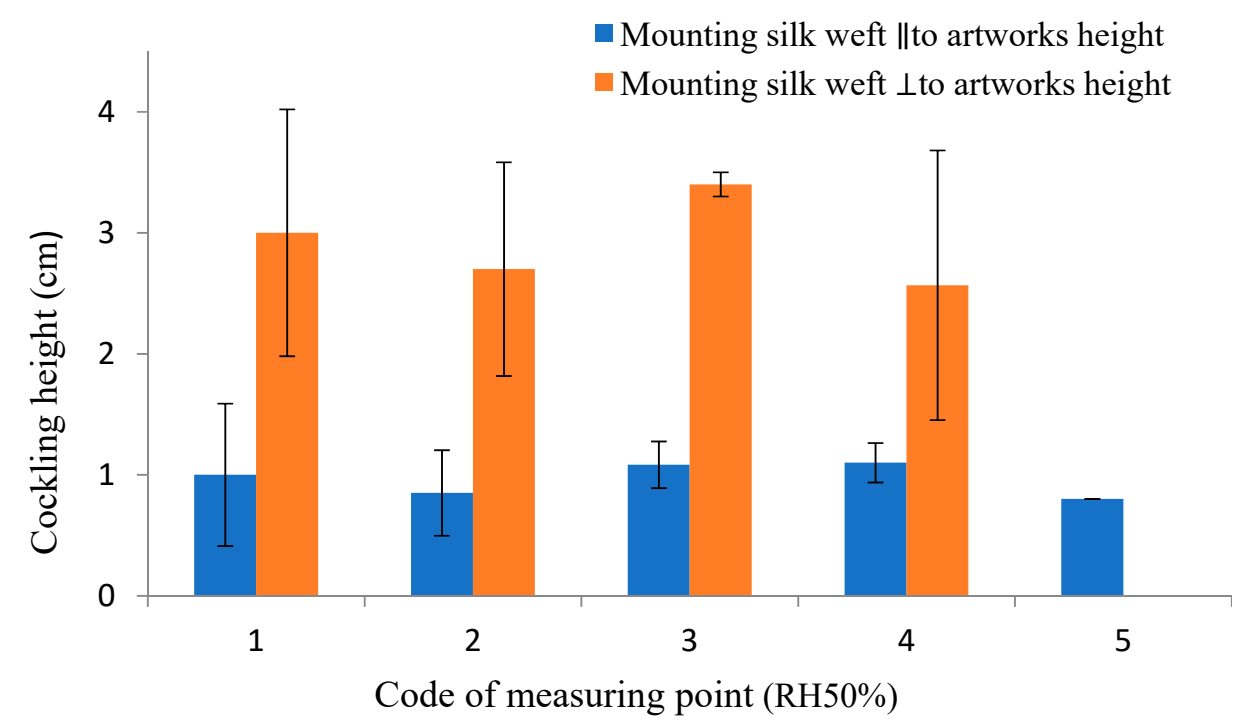

Figure 17. Effects of the weft direction of the mounting silk to the mounted artwork's height direction on its degree of cockling (at $50 \%$ relative humidity).

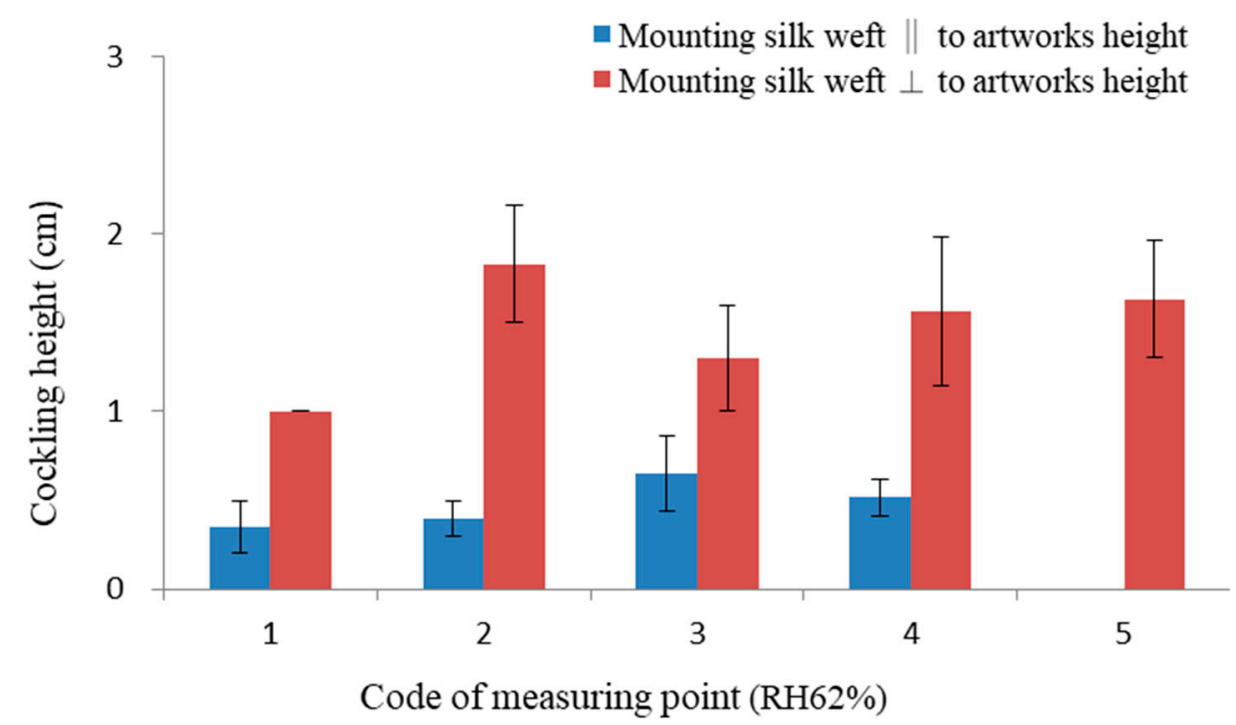

Figure 18. Effect of the weft direction of the mounting silk to the artwork height direction of the mounted artwork on its degree of cockling (at $62 \%$ relative humidity).

Table 2. Effects of the mounting silk warp and weft orientations on the degree of cockling when lifting artwork from a drying board.

\begin{tabular}{ccc}
\hline RH & Direction & Cockling Height (cm) \\
\hline \multirow{2}{*}{ RH 60\% } & Warp & $1.93 \pm 0.62$ \\
& Weft & $0.71 \pm 0.18$ \\
\hline \multirow{2}{*}{ RH 75\% } & Warp & $1.34 \pm 0.36$ \\
& Weft & $0.73 \pm 0.16$ \\
\hline
\end{tabular}

\subsection{Dry Last Backing and Seat Last Backing}

The last backing of an artwork entails dry and seat modes. Due to the greater moisture content of seat last backing, the paper swells more, and after being put on a drying board to dry, the shrinkage stresses are greater. If the paste is brushed on unevenly, the paper will have different swelling stresses, and at the time of lifting from the drying board, the greater 
shrinkage stresses will lead to less even artwork. Hence, mounting practitioners regard seat-backed artworks as having poorer flatness. However, because it uses a thinner paste and is a simpler procedure, many practitioners opt for this practice. With dry last backing, the last backing paper absorbs water from the paste; hence, with a lower moisture content, there is less shrinkage stress during drying and the mounted artwork is considered to be more even. However, as dry last backing uses less water, the paste applied should be thicker and the mounted artwork has a stiffer appearance than that of a seat last backing-mounted artwork.

Table 3 shows the actual cockling heights of dry and seat last backed artwork. Each artwork was measured at the top, middle, and bottom locations, and an average was calculated. From the table, there is little difference between seat- and dry-last backed artworks. Still, dry-last backed artwork had better flatness than seat-last backed ones. Figure 19 shows that dry-last backed work had less overall cockling than the seat-last backed one with better evenness. Seat-last backed works of art use a thinner paste which results in softer, more-pliable mounted artwork. Despite this evidence, this factor is not the main condition affecting cockling of the artwork. In practice, although seat last backing entails more moisture, if water spray is applied to the recto (picture and mounting silk) to even out the moisture content, then the mounted artwork will have similar recto-to-verso moisture distributions, shrinkage will be more uniform, and cockling will be less, leading to a similar effect to that of dry last backing. The only difference is that the thinner paste applied will make it easier to peel away the last backing paper from the artwork. A scholar pointed out that paper shrinkage is related to fiber moisture content. The higher the fiber moisture content is, the greater the shrinkage will be [21]. Thus, when a less wet artwork is attached to board, there will be less shrinkage of the piece upon drying and the stress will naturally be small. Cockling heights of the mounted artwork will be small and relaxed due to the less stress. Final backing with water absorption of the paper leads to lower moisture content, upon attaching to the board, the drying shrinkage stress will naturally be less, and on detachment, the cockling will be more moderate.

Table 3. Effects of dry and seat last backing on cockling heights of typical mounted artwork.

\begin{tabular}{lcccc}
\hline \multirow{2}{*}{ Backing Mode } & \multicolumn{3}{c}{ Cockling Height (cm) } \\
\cline { 3 - 5 } & & Top & Middle & Bottom \\
\hline \multirow{2}{*}{ Seat last backing } & Left & $4.9 \pm 0.05$ & $1.3 \pm 0$ & $3.5 \pm 0.3$ \\
& Right & $4.3 \pm 0.25$ & $1.3 \pm 0$ & $2.9 \pm 0.3$ \\
\hline \multirow{2}{*}{ Dry last backing } & Left & $3.7 \pm 0.35$ & $1.2 \pm 0.3$ & $3.1 \pm 0.1$ \\
& Right & $3.0 \pm 0.45$ & $1.0 \pm 0.05$ & $2.0 \pm 0.45$ \\
\hline
\end{tabular}

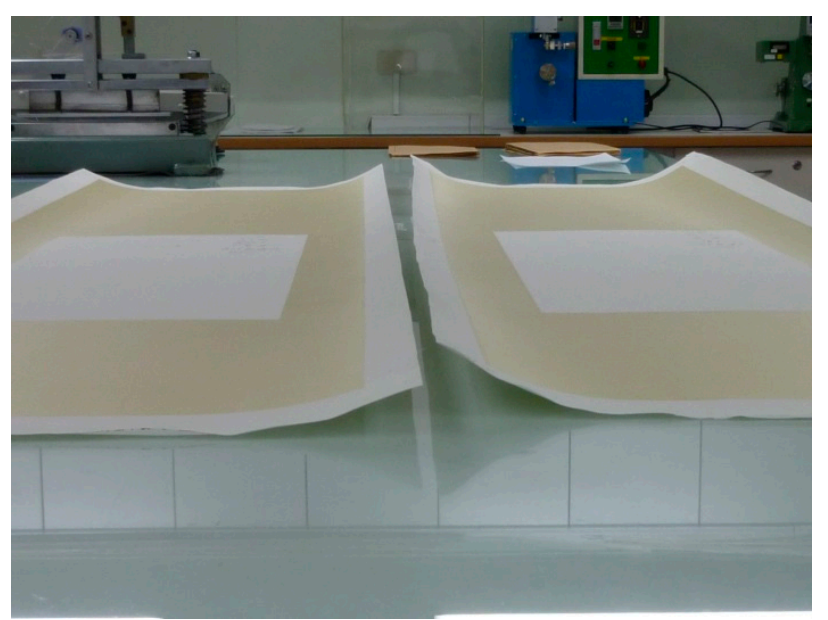

Figure 19. Dry (left) and seat (right) last backing effect on cockling of mounted artworks. 


\subsection{Once and Twice Drying on a Board}

If there is high moisture content when an artwork is backed and attached to a drying board, then the stresses of lifting it from the drying board will be greater, and shrinkage stresses and an uneven distribution of stresses will lead to cockling. If drying on a drying board is omitted, the artwork will not be stretched taut and will appear lumpy and uneven. Therefore, regardless of whether dry or seat last backing is used, some serious mounters detach the artwork from the drying board after the first drying procedure. The artwork is allowed to dry for 1 day. Then, paste is applied to the edges and the artwork is placed flat on the drying board a second time. The second time around, the artwork is not sprayed with water, so it is relatively dry and shrinkage stresses approach zero. The artwork is naturally flatter. The effects of once and twice drying on a drying board of mounted artworks are shown in Figure 20. Results show that regardless of the location of the measurement, twice dried on-boarded artwork exhibited less cockling than once dried on-boarded artwork. The $t$-test results in Figure 20 show that the once-attached to the board artworks and those that were twice attached to the board had significant differences in cockling heights (with $p<0.001$ ). Some scholars pointed out that when paper is dried under a restrained drying condition, the resulting shrinkage will be greater [13]. When the mounted artwork is first attached to the board to dry, due to the higher moisture content and larger swelling, the drying board constitutes restrained drying and the drying stress will be large. When the artwork is attached to the board the second time, the unsprayed piece is akin to unrestrained drying, naturally upon detaching from the board, the artwork will be smoother and less cockled. Some measuring points of the once drying on-boarded artwork had cockling heights more than twice those of twice dried on-boarded artwork. Each measurement point also deviated less in twice on-boarded artwork. In other words, the flatness of the twice dried on-boarded mounted artwork was significantly better than that of the once dried on-boarded artwork. Although this procedure entails an extra day of drying time, it is worth recommending due to the superior results. The raw data of Cockling heights of once and twice on-boarded mounted artworks see Appendix A Table A3.

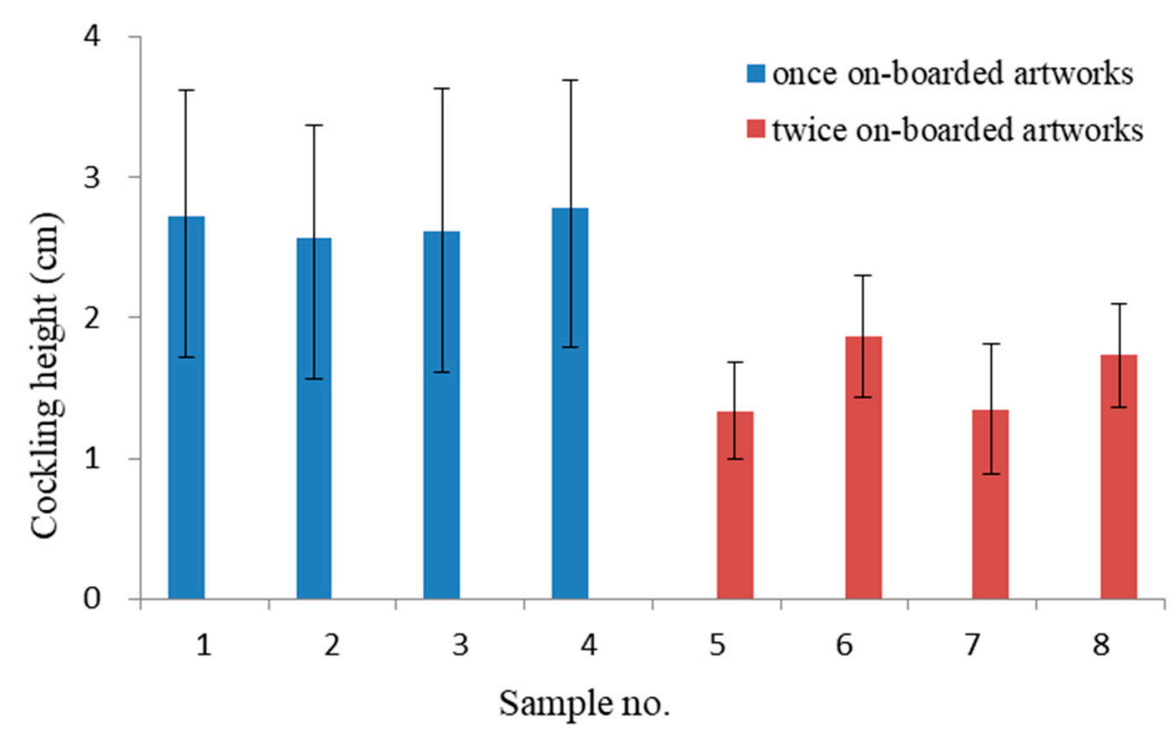

Figure 20. Cockling heights of once vs. twice on-boarded mounted artworks.

\subsection{Waxing and Stone Polishing}

Once traditional hanging scrolls are lifted from the drying board, the verso of the scroll is waxed and stone-polished to make the verso smoother. The purpose is to prevent damage to the artwork due to rubbing when it is rolled up and stored. Our experimental work, however, proved that additionally, because stone-polishing reduces the thickness of the artwork, it makes it more pliable to roll and unroll. During stone-polishing, certain 
raised fibers on the surface of the artwork are crushed and inter-fiber stresses are released, rendering the paper mat more consolidated, which in turn reduces the degree of cockling of the artwork. As the waxing process uses a polishing stone to press the wax into paper interstices, it makes the surface smoother and easier to roll and store. There was a study by a scholar who found that after waxing, the accelerated aging test produced paper with higher folding endurance than paper without waxing [22]. Figure 21 illustrates the cockling heights of artwork before and after polishing after 3, 4, 5, 6, 7, 8, 9, 10, 11, 12, and 14 days of drying durations. The artworks were lifted from the drying board and conditioned for $24 \mathrm{~h}$ before undergoing waxing and polishing. Regardless of the drying duration and mounting silk orientation, waxed and polished artwork had reduced cockling. Summarizing these results, after an artwork is lifted from the drying board, it is recommended that it undergo waxing and stone-polishing treatments. The $t$-test results in Figure 21 indicate that artworks that underwent waxing and polishing had significantly different cockling heights compared to the artworks that did not $(p<0.001)$. The raw data of cockling heights of mounted artworks before and after stone-polishing see Appendix A Table A4.

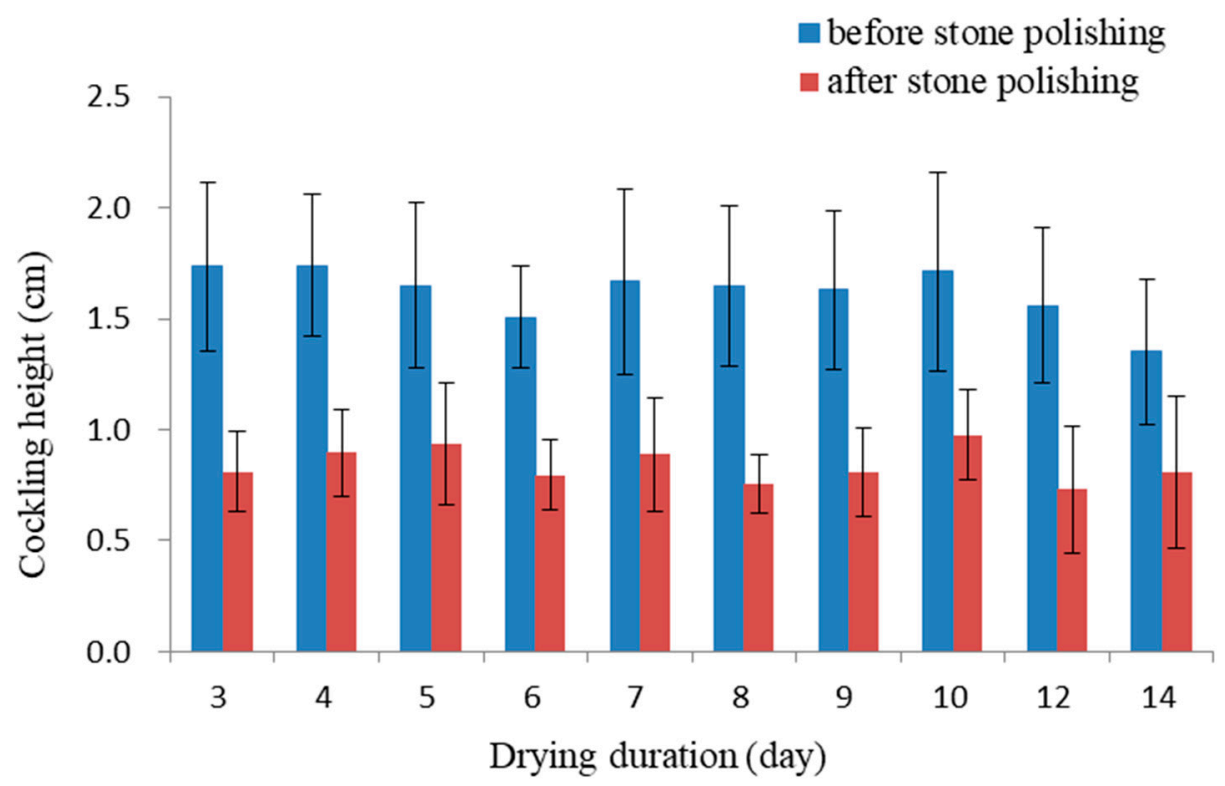

Figure 21. Cockling heights of mounted artworks before and after stone-polishing.

\section{Conclusions}

This study investigated the effects of factors in mounting procedures, such as environmental humidity, drying duration, mounting silk orientation, once and twice drying on a board, mode of last backing, and waxing and stone-polishing, on the flatness of Chinese hanging scrolls. Results indicated that the longer the drying duration, the more moderate the cockling of the mounted artwork became, and the hanging scroll appeared flat and even. We suggest that a drying duration of 4 weeks or more be adopted. Under the three preset environmental moisture contents at the time of lifting from the board, an $\mathrm{RH}$ of $60 \%$ produced the lowest cockling height, whereas $\mathrm{RHs}$ of $50 \%$ and $70 \%$ resulted in greater cockling heights. The weft direction of the mounting silk should be parallel to the artwork height direction. Last backing in the dry mode was better than the seat mode, with dry last backing using a thicker paste than that of seat last backing. Artwork twice dried while mounted on a board had a smaller degree of cockling than that once dried on a drying board, mainly due to reduced shrinkage stresses. Regardless of the length of the drying duration, waxing and stone-polishing also effectively reduced the cockling of mounted artwork. 
Author Contributions: Conceptualization, J.-G.S. and Y.-S.P.; methodology, S.-T.Y.; validation, J.-G.S. and Y.-S.P.; formal analysis, J.-G.S. and Y.-S.P.; investigation, J.-G.S. and Y.-S.P.; resources, J.-G.S.; data curation, J.-G.S., S.-T.Y., and Y.-S.P.; writing-original draft preparation, J.-G.S.; writing-review and editing, S.-T.Y. and Y.-S.P.; supervision, Y.-S.P.; project administration, J.-G.S. and Y.-S.P.; funding acquisition, J.-G.S. All authors have read and agreed to the published version of the manuscript.

Funding: This research was funded by the Taiwan Forestry Research Institute under grant 104AS13.5.3-F-G3.

Institutional Review Board Statement: The study did not involve humans or animals.

Informed Consent Statement: The study did not involve humans or animals.

Data Availability Statement: No data support.

Acknowledgments: We thank everyone who helped this manuscript.

Conflicts of Interest: The authors declare no conflict of interest.

\section{Appendix A}

Table A1. Cockling heights of various drying durations of mounted artworks.

\begin{tabular}{|c|c|c|c|c|c|c|c|c|c|c|c|c|c|c|c|c|c|c|}
\hline \multirow{2}{*}{$\begin{array}{c}\text { Day } \\
3\end{array}$} & \multicolumn{18}{|c|}{ Cockling Height (cm) } \\
\hline & 1.5 & 0.95 & 1.5 & 2.3 & 1.4 & 2 & 1.5 & 1 & 1.35 & 2.3 & 1.35 & 1.9 & 1.45 & 0.95 & 1.45 & 2.4 & 1.2 & 1.65 \\
\hline 4 & 1.75 & 0.7 & 1.8 & 2.1 & 1.4 & 1.95 & 2.2 & 1.05 & 1.9 & 2 & 1.5 & 1.8 & 1.7 & 1.8 & 1.3 & 2.2 & 1.45 & 1.75 \\
\hline 5 & 1.7 & 1.1 & 1.85 & 2.2 & 1.55 & 1.6 & 1.9 & 1.05 & 2.3 & 1.95 & 1.2 & 2.1 & 1.8 & 1.2 & 2.1 & 2.7 & 1.45 & 1.6 \\
\hline 6 & 2.2 & 1.3 & 2 & 1.7 & 1.2 & 2 & 2.3 & 1.55 & 2.15 & 1.95 & 1.35 & 2.5 & 1.65 & 1.3 & 2.2 & 2.05 & 1.35 & 1.7 \\
\hline 7 & 1.8 & 1.3 & 1.35 & 2.35 & 1.3 & 2.2 & 2.2 & 1.3 & 1.8 & 1.8 & 1.1 & 1.2 & 2.4 & 1.6 & 1.9 & 2.2 & 1.2 & 2.4 \\
\hline 8 & 1.85 & 1.3 & 2 & 2.7 & 1 & 1.7 & 2.35 & 1.4 & 1.7 & 2.2 & 1.3 & 1.65 & 2 & 1.3 & 1.4 & 2.15 & 1.3 & 2.1 \\
\hline 9 & 1.85 & 1.1 & 2.05 & 2 & 1 & 1.65 & 2.7 & 1.7 & 2.15 & 2.1 & 1.2 & 1.9 & 2.15 & 1.6 & 1.8 & 2.4 & 1.15 & 1.7 \\
\hline 10 & 2.15 & 1.6 & 2.15 & 2.2 & 1.05 & 2.5 & 2.4 & 1.4 & 2.35 & 2.2 & 1.1 & 2.3 & 2.15 & 1.6 & 2 & 2.1 & 1.05 & 2.3 \\
\hline 12 & 1.85 & 1.5 & 1 & 1.6 & 1.1 & 1.7 & 2 & 2 & 1.4 & 1.9 & 1 & 1.5 & 1.9 & 1.55 & 1.65 & 1.95 & 1.15 & 2.2 \\
\hline 14 & 1.75 & 1.3 & 1.85 & 2 & 1.05 & 0 & 2.2 & 1.6 & 2.5 & 2.25 & 0.95 & 2.25 & 2.4 & 1.3 & 2.55 & 2.3 & 1 & 2.65 \\
\hline 21 & 0.8 & 0.8 & 0.5 & 0.7 & 0.8 & 0.5 & 0.6 & 0.2 & 1.2 & 0.6 & 0.4 & 0.1 & 0.8 & 0.2 & 0.1 & 1.2 & 0.5 & 0.4 \\
\hline 28 & 0.2 & 0.4 & 0.4 & 0.4 & 0.4 & 0.3 & 0.7 & 0.5 & 0.5 & 1.1 & 0.6 & 0.5 & 0.5 & 0.2 & 0.5 & 1.5 & 0.4 & 0.6 \\
\hline 42 & 1.3 & 0.5 & 0.6 & 0.5 & 0.5 & 0.1 & 0.6 & 0.8 & 1 & 0.5 & 0.5 & 0.3 & 0.4 & 0.6 & 0.7 & 0.7 & 0.6 & 0.7 \\
\hline 60 & 0.8 & 0.4 & 0.4 & 0.85 & 0.55 & 0.85 & 1.05 & 0.25 & 0.6 & 1 & 0.15 & 0.2 & 0.95 & 0.6 & 0.85 & 0.4 & 0.2 & 0.2 \\
\hline 90 & 0.3 & 0.65 & 0.35 & 0.4 & 0.65 & 0.6 & 0.45 & 0.45 & 0.25 & 0.15 & 0.55 & 0.45 & 0.65 & 0.5 & 0.4 & 0.5 & 0.55 & 0.55 \\
\hline 180 & 0.3 & 0.7 & 0.45 & 0.55 & 0.75 & 0.3 & 0.65 & 0.2 & 0.35 & 0.3 & 0.3 & 0.7 & 0.45 & 0.4 & 0.65 & 0.65 & 0.05 & 0.15 \\
\hline 300 & 0.6 & 0.3 & 0.2 & 0.6 & 0.3 & 0.2 & & & & & & & & & & & & \\
\hline
\end{tabular}

Table A2. Cockling heights of the weft direction of the mounting silk to the artwork height direction of the mounted artwork.

\begin{tabular}{ccccccc}
\hline & \multicolumn{2}{c}{ Silk Weft } & \multicolumn{2}{c}{ Artwork Height } & \multicolumn{3}{c}{ Silk Weft $\perp$ Artwork Height } \\
\hline RH(\%) & Top & Middle & Bottom & Top & Middle & Bottom \\
\hline & 0.4 & 0.15 & 0.5 & & & \\
& 0.5 & & 0.3 & & 1 & \\
62 & 0.35 & 0.8 & 0.8 & 2.2 & 1.4 & 1.9 \\
& 0.5 & 0.4 & 0.65 & 1.2 & 1 & 1.7 \\
& & & & 1.7 & 1 & 2 \\
& & & & 1.7 & 1.2 & 4 \\
& 1.6 & 0.2 & 1.2 & 3.4 & 1.6 & 3 \\
& 1.1 & 0.35 & 1.1 & 3.6 & 1.5 & \\
& 1.35 & 1 & 0.9 & & & \\
& 1.1 & 0.9 & 1.3 & & & \\
& & 0.8 & & 3.5 & & \\
\end{tabular}

II: The weft direction of the mounting silk parallel to the artwork height direction. $\perp$ : The weft direction of the mounting silk perpendicular to the artwork height direction. 
Table A3. Cockling heights of once vs. twice on-boarded mounted artworks.

\begin{tabular}{ccccccc}
\hline & Top & Middle & Bottom & Top & Middle & Bottom \\
\hline once & 3.8 & 1.55 & 2.8 & 3.2 & 1.2 & 3.45 \\
on-board & 3.6 & 1.6 & 2.5 & 3.7 & 1.55 & 3.1 \\
\hline twice & 1.4 & 1 & 1.6 & 1.1 & 0.95 & 2 \\
on-board & 2.5 & 1.2 & 1.9 & 2.2 & 1.3 & 1.7 \\
\hline
\end{tabular}

Table A4. Cockling heights of mounted artworks before and after stone-polishing.

\begin{tabular}{|c|c|c|c|c|c|c|c|c|c|c|c|c|c|c|c|c|c|c|}
\hline \multirow{3}{*}{$\begin{array}{c}\text { Day } \\
3\end{array}$} & \multicolumn{18}{|c|}{ Before Stone-Polishing } \\
\hline & \multicolumn{18}{|c|}{ Cockling Height (cm) } \\
\hline & 1.5 & 0.95 & 1.5 & 2.3 & 1.4 & 2 & 1.5 & 1 & 1.35 & 2.3 & 1.35 & 1.9 & 1.45 & 0.95 & 1.45 & 2.4 & 1.2 & 1.65 \\
\hline 4 & 1.75 & 0.7 & 1.8 & 2.1 & 1.4 & 1.95 & 2.2 & 1.05 & 1.9 & 2 & 1.5 & 1.8 & 1.7 & 1.8 & 1.3 & 2.2 & 1.45 & 1.75 \\
\hline 5 & 1.7 & 1.1 & 1.85 & 2.2 & 1.55 & 1.6 & 1.9 & 1.05 & 2.3 & 1.95 & 1.2 & 2.1 & 1.8 & 1.2 & 2.1 & 2.7 & 1.45 & 1.6 \\
\hline 6 & 2.2 & 1.3 & 2 & 1.7 & 1.2 & 2 & 2.3 & 1.55 & 2.15 & 1.95 & 1.35 & 2.5 & 1.65 & 1.3 & 2.2 & 2.05 & 1.35 & 1.7 \\
\hline 7 & 1.8 & 1.3 & 1.35 & 2.35 & 1.3 & 2.2 & 2.2 & 1.3 & 1.8 & 1.8 & 1.1 & 1.2 & 2.4 & 1.6 & 1.9 & 2.2 & 1.2 & 2.4 \\
\hline 8 & 1.85 & 1.3 & 2 & 2.7 & 1 & 1.7 & 2.35 & 1.4 & 1.7 & 2.2 & 1.3 & 1.65 & 2 & 1.3 & 1.4 & 2.15 & 1.3 & 2.1 \\
\hline 9 & 1.85 & 1.1 & 2.05 & 2 & 1 & 1.65 & 2.7 & 1.7 & 2.15 & 2.1 & 1.2 & 1.9 & 2.15 & 1.6 & 1.8 & 2.4 & 1.15 & 1.7 \\
\hline 10 & 2.15 & 1.6 & 2.15 & 2.2 & 1.05 & 2.5 & 2.4 & 1.4 & 2.35 & 2.2 & 1.1 & 2.3 & 2.15 & 1.6 & 2 & 2.1 & 1.05 & 2.3 \\
\hline 12 & 1.85 & 1.5 & 1 & 1.6 & 1.1 & 1.7 & 2 & 2 & 1.4 & 1.9 & 1 & 1.5 & 1.9 & 1.55 & 1.65 & 1.95 & 1.15 & 2.2 \\
\hline 14 & 1.75 & 1.3 & 1.85 & 2 & 1.05 & 0 & 2.2 & 1.6 & 2.5 & 2.25 & 0.95 & 2.25 & 2.4 & 1.3 & 2.55 & 2.3 & 1 & 2.65 \\
\hline \multicolumn{19}{|c|}{ After Stone-Polishing } \\
\hline 3 & 0.75 & 0.6 & 0.8 & 0.5 & 0.7 & 0 . & 0.8 & 0. & 0.9 & 0.9 & 0. & 0.9 & 0.7 & 0.6 & 0.65 & 1.3 & 0.75 & 0.85 \\
\hline 4 & 0.9 & 0.4 & 0.9 & 1.25 & 1.05 & 0.85 & 1.1 & 0.6 & 1 & 0.9 & 0.8 & 0.6 & 1 & 0.55 & 0.7 & 1.2 & 0.9 & 0.6 \\
\hline 5 & 0.85 & 0.65 & 0.8 & 1.2 & 1.05 & 0.7 & 0.75 & 0.6 & 0.85 & 1 & 0.8 & 1.1 & 0.95 & 0.85 & 1.75 & 1.6 & 1 & 1.1 \\
\hline 6 & 1.15 & 0.8 & 0.9 & 0.7 & 0.7 & 0.8 & 1.1 & 1 & 1.3 & 1 & 0.75 & 0.8 & 0.45 & 0.75 & 0.9 & 1 & 0.9 & 0.9 \\
\hline 7 & 0.9 & 0.95 & 0.65 & 1.05 & 0.65 & 0.95 & 1.4 & 0.9 & 0.7 & 0.9 & 0.6 & 0.45 & 1.15 & 1.2 & 0.85 & 1.25 & 0.7 & 1.05 \\
\hline 8 & 1 & 0.8 & 0.9 & 1.5 & 0.65 & 0.7 & 1.1 & 1 & 0.7 & 0.6 & 0.7 & 0.7 & 0.9 & 0.85 & 0.7 & 0.6 & 0.7 & 0.6 \\
\hline 9 & 1 & 0.65 & 0.5 & 0.85 & 0.6 & 0.5 & 1.5 & 1.15 & 1.15 & 0.7 & 0.8 & 0.85 & 1.4 & 1.1 & 0.95 & 1.1 & 0.7 & 0.95 \\
\hline 10 & 1.25 & 1.1 & 1 & 1.3 & 0.6 & 1.2 & 1.5 & 1.05 & 1.3 & 1.2 & 0.7 & 1.1 & 1.1 & 1 & 0.8 & 1.15 & 0.75 & 1.25 \\
\hline 12 & 0.9 & 0.8 & 0.8 & 0.05 & 0.7 & 0.15 & 1.3 & 1.3 & 0.6 & 0.9 & 0.6 & 0.65 & 1.05 & 0.85 & 0.7 & 1.1 & 0.75 & 1.1 \\
\hline 14 & 1.15 & 0.7 & 1 & 1.1 & 0.35 & 0.2 & 1.4 & 1 & 1.35 & 0.6 & 0.6 & 1.1 & 1.25 & 0.8 & 0.9 & 1.4 & 0.6 & 1 \\
\hline
\end{tabular}

\section{References}

1. Fong, Z.M. Mounting of Chinese Artworks; Shandong Science and Technology Publishing Co.: Shandong, China, 1997 ; pp. $103,173$. (In Chinese)

2. Kang, J.K. Methods of Mounting Chinese Artworks, 1st ed.; Sichuan Science and Technology Publishing Co.: Sichuan, China, 2005; p. 218. (In Chinese)

3. Ma, H.P. How to overcome cockling and deformation of artworks using traditional mounting techniques. Chin. Mus. 1996, 4, 87-94.

4. Research Unit of Chinese Artworks Mounting Crafts College. The Art of Mounting Chinese Artwork, 1st ed.; Chilu Books Co.: Jinan, China, 2002; pp. 10-35. (In Chinese)

5. Tu, B.Z.; Tu, T.S. Compilation and Explanation of the Art of Mounting Chinese Artworks, 4th ed.; Shanghai Books Publishing Co.: Shanghai, China, 1999; pp. 11, 62, 236. (In Chinese)

6. $\mathrm{Li}, \mathrm{T}$. Introduction to the causes and treatment methods often encountered in the process of mounting Chinese artworks. In Proceedings of the 1st East Asia Paper Protection Symposium, Beijing, China, 27-28 May 2006; Science Publishing Co.: Beijing, China, 2008; pp. 118-132. (In Chinese).

7. Li, T. Effects of paper caliper and roll-up diameter on the artwork properties. Sci. Cons. Arch. 2013, 25, 25-34. (In Chinese)

8. Yang, Z.C. Complete Guide to Mounting Chinese Artworks, 1st ed.; Shandong Art Publishing Co.: Shandong, China, $1997 ;$ p. 114. (In Chinese)

9. Shen, W.Z. Studying Qi-Wa Phenomenon in Scrolls-Edge Culing. Ph.D. Thesis, Tsing Hua University, Taiwan, China, 2013. (In Chinese).

10. Hayakawa, N.; Kimijima, T.; Kusunoki, K.; Oka, Y. The adhesive effect of uchibake (beating brush) in Japanese Paper Conservation. Sci. Cons. 2004, 43, 9-16.

11. Nielsen, I.; Priest, D. Dimensional stability of paper in relation to lining and drying procedures. Pap. Conserv. 1997, 21, 26-36. [CrossRef] 
12. Larsson, P.A.; Wågberg, L. Influence of fibre-fibre joint properties on the dimensional stability of paper. Cellulose 2008, 15, 515-525. [CrossRef]

13. Hofmann, C.; Baker, M.; Van Der Reyden, D. The Effect of Three Humidification, Flattening and Drying Techniques on the Optical and Mechanical Properties of New and Aged Transparent Papers; Institute of Paper Conservation: Manchester, UK, 1992; pp. 247-256.

14. Uesaka, T.; Kodaka, I.; Okushima, S.; Fukuchi, R. History-dependent dimensional stability of paper. Rheol. Acta 1989, 28, 238-245. [CrossRef]

15. Oba, T. Kakemono: Japanese hanging scroll. Pap. Conserv. 1985, 9, 13-23. [CrossRef]

16. Nishio, Y. Maintenance of East Asian painting (examination). Book Pap. Group Annu. 1993, 12, 32-35.

17. Yeh, Z.R. The Methods and Treatments of Retaining the Original Mounting Materials for Hanging Scrolls. Master's Thesis, Taiwan National University of the Arts, Taiwan, China, 2011. (In Chinese).

18. Smook, G. Handbook for Pulp and Paper Technologists, 4th ed.; TAPPI Press: Atlanta, GA, USA, 2016; p. 352.

19. Yamazaki, H. New functions of wood fiber cell walls found during absorption and desorption of moisture. Jpn. J. Pap. Tech. 2020, 63, 35-47.

20. Hsu, W.J. Dealing with the cockling problem of artworks based on the hidden properties of Xuan paper. In Proceedings of the 1st East Asia Paper Protection Symposium, Beijing, China, 27-28 May 2006; Science Publishing Co.: Beijing, China, 2008 ; pp. $110-117$. (In Chinese).

21. Sampson, W.W.; Yamamoto, J. The drying shrinkage of cellulosic fibres and isotropic paper sheets. J. Mater. Sci. 2011, 46, 541-547. [CrossRef]

22. Yeh, C.C. The Study of Wax Used in Chinese Painting. Master's Thesis, Yunlin University of Science and Technology, Taiwan, China, 2005. (In Chinese). 